\title{
Sociocultural Factors Associated with the $S$ Éroprévalence of Infection HIV in Kenge, DRC (January 2015-June 2016)
}

\author{
Benjamin Ngongo Mulemba ${ }^{1}$, Perpétue Zenga Mukinda ${ }^{2,3 *}$, Felix Pindi Piay ${ }^{2}$, Zachariah Kibanda \\ Kidiatata $^{2,4}$, Perpetua Nganda Kitonguna ${ }^{2,5}$, Wivine Nzoko Ngana ${ }^{2,5}$ and Alphonsine Mambi Tsanga ${ }^{2}$ \\ ${ }^{1}$ Professor Associe, Higher Institute of Medical Techniques Mary Queen of Peace Kenge, DRC \\ ${ }^{2}$ Assistant, Superior Institute of Medical Techniques Marie Rein e Peace of Kenge, Kenge, RDC \\ ${ }^{3}$ Nurse Supervisor, Kenge Health Zone, Kwango Province, DRC
}

${ }^{4}$ Nursing Director, Kenge Reference General Hospital, Kwango Province, DRC

${ }^{5}$ Nurse, Kenge Reference General Hospital, Kwango Province, DRC

*Corresponding author: Perpétue Zenga Mukinda, Assistant, Superior Institute of Medical Techniques Marie Rein e Peace of Kenge, Kenge, RDC; Nurse Supervisor, Kenge Health Zone, Kwango Province, DRC

\begin{abstract}
ARTICLE INFO
Received: 慧 May 06, 2019

Published: May 28, 2019

Citation: Benjamin Ngongo M, Perpétue Zenga M, Felix Pindi P, Zachariah Kibanda K, Perpetua Nganda K, Wivine Nzoko $\mathrm{N}$, Alphonsine Mambi T. The Issue of Solid Household Waste Management in the Mateba Health Area (Ngaba), Kinshasa, DRC. Biomed J Sci \& Tech Res 18(2)2019. BJSTR. MS.ID.003137.
\end{abstract}

Keywords: Screening; HIV / AIDS; Seropositive Prevalence
ABSTRACT

HIV infection is cosmopolitan Among the Most dreadful diseases That Remains a major concern of public health. According to UNAIDS (2017), 36.7 million people live with HIV / AIDS, among whom 70\% live in Sub Saharan Africa. This study is intended to provide a clear answer to the questions: what is the trend of the infection in the city of Kenge? And to what sociocultural factors associated ca No one at e it? The stud y w a s essentially re trospective based we have a descriptive design and a survey supported by a documentar yr e view and a structured interview on seropositive patients from January 2015 to June 2016. Results indicate that a total of 19 percent of 655 were screened for positive H IV infection. Further observations on the expl has n Tory variable Helped clearing the way to the Existing tr ends in the Evolution of HIV/AIDS infection in the city. Hen this, the prevalence of the infection in Kenge city Was established at 2.9\%, a rate that is beyond the national threshold of $1.1 \%$.

Patients whose age was beyond 14 years, those of female gender and living in the Congo, Kikwit and Bakali / SAS neighborhoods were most affected. The Major Reason Is That thesis neighbourhoods are along the National 1highway (Kinshasa-Kikwit), where Several houses of easing That offer has no shelter to a large flow of migrants to take a rest, rejoicead engage in sexual activities, which are mostly unprotected. In all of this, the l act of Knowledge on the transmission and prevention of HIV / AIDS consisting teams in the case of this significant seropositive prevalence of HIV in the city of Kenge; However, affiliation to a religion or an ethnic group do es not Significantly affect it. Hence, the authors vividly recommend the Congolese Government to support the Ongoing activities aiming at fighting HIV / AIDS in order to receipt prevalence. sensitization ie s activities aiming at screening HIV infection and at Promoting the use of preservatives, the distribution of condoms, and the caretaking ailing patients are Among precautionary me safe to be taken in or $\mathrm{d}$ e $\mathrm{r}$ to eradicate this flea.

\section{Summary}

HIV infection is one of the most deadly cosmopolitan diseases and remains a major public health concern. According to UNAIDS (2017), 36.7 million people live with HIV / AIDS, 70\% of them in sub-Saharan Africa. This study was to respond clearly and unequivocally to the question: What is an evolutionary trend of HIV infection in the town of Kenge? And to which socio-cultural factors can we associate it? The study was mainly referred to retrospective descriptive e based on a survey supported by the literature review 
and a structured interview to identify HIV-positive from January 2015 to June 2016. A total of 19 out of 655 people were screened for HIV positive. The observations made on each of the explanatory variables have enabled emerges trends of the past. In addition, the prevalence of HIV infection was 2.9\%; which exceeds the threshold national 1.1\%. The patients aged over 14 years, those females and living areas are the Congo Kikwit and Bakali / SAS, were the most affected. Indeed, these neighborhoods are located along the National Highway No. 1 (Kinshasa-Kikwit) where places of ease swarm to provide a roof to a large flow of migrants to rest, to rejoice and to have sex, which for the most part are unprotected. In all this, the lack of knowledge about transmission and prevention HIV / AIDS is the main cause is this important sero prevalence in the town of Kenge; membership religi honest and Ethni $n$ e influence not significatively. The authors urged the government congolais support activities against HIV / AIDS to reduce the prevalence of this pandemic. Awareness-raising activities on condom screening and condom use, condom distribution and case management are all measures.

\section{Introduction}

HIV infection is one of the most deadly cosmopolitan diseases. Today, it is a major scourge that affects human capital and its magnitude and consequences have a negative impact on all development sectors (UNAIDS, 2005). With more than 35 million deaths to date, HIV continues to be a major global public health problem (WHO, 2017). According to the WHO report [1], 36.7 million people s worldwide are infected with HIV, of which approximately $70 \%$ live in sub-Saharan Africa. Infection damages families slows growth and robs countries of valuable skills (Koffi Annan, 2004). Despite diligent past 30 years in the sought-e since its discovery these days, its particularly deadly pathogenicity explains all the dynamics of control strategies developed around the world [2]. In Eastern Europe, Central Asia, the Middle East, North Africa and many parts of Asia and Latin America, drug use is the leading cause of new HIV infections [3-5]. In several regions, a substantial portion of the NEW infections is due to the fact that the collection of blood and transfusions are in bad conditions and the use of contaminated needles [6]. In its report on the situation of HIV / AIDS in the world, UNAIDS (2008) accredits DHS data -2008 situating the national prevalence of DR Congo in the range of 1.2 to $1.5 \%$ [7]. The national seroprevalence of the DRC is therefore one of the lowest in the region.

In contrast, the serosurveillance report in 2011 indicates a prevalence of $1.1 \%$ in the general population (UNAIDS and WHO, 2013). The HIV / AIDS epidemic in the DRC has remained relatively stable over the last 5 years (MINISANTE, 2010) [8]. Data from sentinel sites show that the HIV / AIDS epidemic is widespread in the DRC. Current trends i n diqu ent that this epidemic ruralized (4.6\% in rural areas compa $4.2 \%$ in urban areas) is "juvénilise" and feminization (sex ratio: 1.3), especially in railway stations, seaports, mining areas and border posts (Balangaliza, 2007). HIV affects an impressive number of people and access to antiretrovirals (ARVs) is very limited yet considered as the only effective treatment that can significantly improve the quality and length of life of people living with HIV [9]. Over one million people are HIV positive in the DRC and the estimated rate of e patients at an ARV coverage to $14 \%$. This coverage rate is among the lowest in the world, and significantly lower than neighboring countries [10]. Similarly, the treatment of Prévention of Transmission of HIV M era in Enfant (PMCT) $n$ is available only for $1 \%$ of women infected with HIV, which is extremely low compared to neighboring countries (UNAIDS, 2015) [8].

In addition, a very large majority of people affected by HIV / AIDS in the DRC do not know their HIV status. Low screening is explained by the lack of VCT / PITC in several health facilities and supplies inadéqua $t$ test $s$ HIV. Other factors influence this low population screening, including stigma, discrimination, fear of being rejected by relatives, shame or lack of available ARV treatment. (UNAIDS 2015). In 2016, HIV prevalence in Kwango was around $0.3 \%$ of the general population, among the which has the nearly $92 \%$ were on ART (MOH 2016). In those days, then what is the dan $t$ in this evolving of HIV / AIDS infection in the town of Kenge? And, what socio c ulturels can we associate it? This is what is striving to answer this study aimed to determine the socio-cultural factors that expli nt prevalence of HIV / AIDS infection in the town of Kenge, as the s plane s sociodemographic than educational. It is s pécifiquement enumerate the population who carried out the screening test, dégag st the positives are, and then catégoris st infected subjects by age, sex, place of residence, religion, language group, perception and knowledge. Second, the study may infer socio demographic and educational factors s associated with sero prevalence of HIV / AIDS infection in Kenge City from January 2015 to June 2016.

\section{Literature Paper}

The distribution of S IDA around the world is, as many studies suggest, very disproportionate. Such disproportion is seen as a logical consequence of the often-singular situations that prevail in each country. An analysis of the different available data reveals many geographical trends (MINI PLAN, 2007). The latter depend considerably on several determining factors among which, access to prevention and screening services, the context of precariousness of life, promiscuity, the precocity of sexual intercourse and other sexual practices such as the multi-sexual partnership, population mobility, state of security in the country, common awareness practices, availability of drugs [11]. It has been observed that since the introduction of ARVs, the seropositivity no longer appears to patients, their families, their relatives or caregivers, as a declaration of death even though the prevalence is higher among men than women. (PNMLS, 2012). This suggests that antiretrovirals are a real breakthrough in the fight against HIV / AIDS, as they turn a oncedeadly disease into a potentially chronic disease [11]. With regard to the lifestyle conducted, other available data confirm a close link between certain manias and HIV infection. Paid sex and alcohol use, for example, have a significant exposure to this infection [12]. 
It is now accepted that men who have paid sex are more likely to be physically abusive towards their partners, to have a high number of partners, to consume heavily and to violate. Data from the DHS reconfirm this correlation of Violences between Partenaires in times (VPI) and alcohol consumption (Harvard Unversity, 2006). Awareness plays a role in improving knowledge about this pandemic. In Southern Africa, for example, it is documented that when awareness-raising activities on gender and AIDS accompany the implementation of microfinance projects for 12 months, two years later, a higher level of knowledge about HIV is identified. and HIV testing, increased condom uses with non-marital partners, 55\% reduction in physical and sexual violence between intimate partners (UNDP-DRC, 2010). These advances constitute a revolution that is not only medical. It is also the basis of a real change in the popular perceptions of AIDS (Olivier, 2006). Like education, education also has a lot to do with advances in HIV / AIDS testing and care. The risk of contraction of AIDS is related to the level of education [13]. Well integrated, all the benefits gained should lead to a decline in prevalence. According to estimates, HIV / AIDS is ranked as the fourth leading cause of death in the world with 39.5 (CI 34.1 - 47.1) million HIV carriers. In 2006, new infections occurred at about 4.3 million (IC 3.6- 6.6) and deaths were estimated at 2.9 million (IC 2.5 - 3.5) [14].

For all available sources, sub-Saharan Africa is the region most affected by the epidemic and HIV is the main cause of death in this region, which is estimated to have been recorded in the same year 2.8 (IC 2.4 - 3.2) million new infections [14]. In 2006, Mali, with a population estimated at 12,250,019 inhabitants, had an estimated seroprevalence of $1.3 \%$ with $1.1 \%$ among men and $1.5 \%$ among women [15]. Counted among the most affected countries, DR Congo presents different tables, changing according to whether one is east or west and from one year to another. By dividing the Democratic Republic of Congo into two large "West" and "East" zones, populations in the regions and provinces in the east of the country are twice as prevalent as those in the West. the exception of Kinshasa [16]. In the east of the country, the mortality of infected women is twice as high as among western women (Benjamin, 2009). Rape and sexual violence fostered by widespread insecurity are the basis of this high prevalence in Part Est. There is also reason to fear that the same situation will reoccur in the center of the country faced with the same insecurity. These factors are amplified by widespread poverty in some settings and socio-cultural barriers. (PNMLS, 2012). Estimated at 4\% for the entire period from 2003 to 2011 , this prevalence dropped to $3.4 \%$ of the 974,304 PHAs, of whom 439,137 were eligible for ART in 2012, reaching 1.1 in 2013 [17] (UNAIDS, 2013).

\section{Materials and Methods}

\section{Description of the mi Place of Study}

This field study conducted in the city of Kenge's neck u r s the period of th January 2015 to June 2016. The city has an e population depress 300.000 divided into 15 districts [18]. It is to evenue capital Province Kwango when decentralization held in the Democratic Republic of Congo $\mathrm{n}$ th, 2016. The town of Kenge is located at $5^{\circ} \mathrm{S}$ latitude, $17^{\circ}$ East longitude, and at an average elevation of $555 \mathrm{~m}$ above the sea surface [19]. Its climate is humid tropical. The city is entirely on plateaux intersected by valleys, and sometimes, hills between the rivers Wamba in the west and Bakali in the east. The Kenge soil is sandy Karoo-Kalahari type. Its vegetation consists essentially of grassy savannahs, woodlands and forest galleries found along the rivers. The city is connected to the rest of the country mainly by the National Road $\mathrm{N}^{\circ} 1$, Kinshasa-Kikwit.

\section{Sampling and Technique Collection of Donations}

This study was essentially descriptive retrospective based on a survey supported by the literature review and a structured interview to identify HIV-positive people during the research period. The sample in this study was simple random probabilistic. Its size was calculated by the Fisher formula and s' is raised to 655 people who carried out the voluntary testing. Data collection was done in the structures CDV / DCIP Kenge during the period from e Janver 2015 at Y oun 2016. The enquêt century were made on appointments, obtained prior ment before $\mathrm{d}$ or $\mathrm{r}$ the interview with the heads of structures under investigation.

Selection Criteria: The following subjects were included in the study sample:

(i) living in the town of Kenge;

(ii) have been consulted in the CDV / DCIP structures during the period of our study; and

(iii) have been tested positive for HIV.

\section{Criteria for Exclusion}

Was excluded from the sample, any person having voluntarily refused to participate in the study or having been absent during the investigations.

\section{S Technical Data Analysis}

The analyzes were mainly based on descriptive statistics. The data has been tabulated to facilitate the calculation of frequencies. The trends were identified for using the following formulas:

$$
f=\frac{F o}{F A} * 100 \quad \text { [Equation 1] }
$$

Or,

$\mathrm{f}=$ Relative frequency

FO $=$ Frequency observed

$\mathrm{FA}=$ Expected frequency

$$
p=\frac{X}{N} * 100
$$

Or, 
$p=$ Prevalence

$\mathrm{x}=$ Number of positive cs

$\mathrm{N}=$ Total number of cases identified

The chi-square statistic ( $\mathrm{chi}^{2}$ or $\mathrm{X}^{2}$ ) was used to test the null hypothesis that there was no significant relationship between the expected distribution of seroprevalence (E) and observed that e of presumed socio-psychological factors influence the seroprevalence (0). Thus, the century following assumptions have been testing e e s:

a) H0: $E \neq 0$, there is a significant difference ent $r$ e distributions of $\mathrm{E}$ and $\mathrm{O}$

b) $\mathrm{H} 1 \mathrm{E}=\mathrm{O}$, There ' $\mathrm{a}$ a u cu not significant difference between the $\mathrm{E}$ and $\mathrm{W}$ of distributions

From an analytical point of view, the chi-square statistic $\left(\mathrm{Khi}^{2}\right.$ or $\mathrm{X}^{2}$ ) is represented by the following formula (Equation 3 ):

$$
\chi_{d d l ; p}^{2}=\sum \frac{\left(E_{j}-O_{i}\right)^{2}}{O_{i}}
$$

[ Equation 3]

Where,

$E_{i}$, the $i^{\text {th }}$ expected number of seropositive patients

$\mathrm{O}_{j}$, the $j^{\text {th }}$ observed effective da ns distribution alleged socioeconomic factors explain seroprevalence

$\mathrm{ddl}$, the degree of freedom (equal to $\mathrm{nk}$ )

$\mathrm{n}$, the total number of the sample

$\mathrm{k}$, the number of estimated parameters (equal to the number of factors) Ho)

p, the signi fi cation rate (equal to the probability of failure of

The chi-square $\left(\mathrm{Khi}^{2}\right)$ statistic was tested at the $5 \%$ significance level $(p=0.05$ ) using SPSS 12.0 and MS Excel 2010 computer software.

\section{Results of Analysis}

\section{Analysis of Socio - Demographic Characteristics of Respondents}

The results of $u$ Table 1 reveal that the 655 people tested for HIV, 293 were cases of e male (44.7\%) and 362 were of a female (55.3\%). The prevalence of infection e u s HIV is eventually raised to $2.9 \%, 19$ times out of 655 (Table 1). L HIV prevalence by age brackets was $2.4 \%$ for the 6 th century to 14 years and $3.4 \%$ for those 4 years plus 1 . The at rs categories recorded no active cases of HIV infection (Table 2). The results in Table 3 reveal that out of a total of 19 subjects, 13 cases were detected at the General Hospital VCT. of Reference (HGR) of Kenge (68\%) 4 cases detected at the CDV of the CS de la Barrière (21\%); and 2 cases detected at the CDV of CS Mgr. Jean-Gaspard Mudiso / Dream of Kenge (11\%) (Table 3). Table 4 indicates that the majority of cases were screened in 2015 (16 cases, 84\%); only 3 cases were in 2016 (16\%) (Table 4). The distribution of respondents according to the mid place of origin shows a high concentration of subjects carrying the HIV virus in Congo neighborhoods, Kikwit and Bakali / SAS. Indeed, the district of Congo had more cases of HIV positive than the others (with 6 cases, 31.6\%) followed by Kikwit and Bakali / SAS (with respectively 5 cases, or $26.3 \%$ ). The Masikita district recorded 2 cases $(10.5 \%)$ and the EPOM district shone with a very low HIV prevalence of $5.3 \%$ (only 1 case) (Table 5).

Table 1: Sex Distribution of HIV-Tested People.

\begin{tabular}{|c|c|c|c|c|}
\hline & \multicolumn{2}{|c|}{ Surveyed Population } & \multicolumn{2}{c|}{ Prevalence } \\
\hline Sex & Effective & Percent (\%) & (Cas +) (\%) & (Cas-) (\%) \\
\hline Male & 293 & 44.7 & $5(1,7)$ & $288(98.2)$ \\
\hline Female & 362 & 55.3 & $14(3.8)$ & $348(96.1)$ \\
\hline Total & 655 & 100 & $19(2.9)$ & $636(97.0)$ \\
\hline
\end{tabular}

Source: Author's (201 7).

Table 2: Distribution of people tested for HIV by age group.

\begin{tabular}{|c|c|c|c|c|}
\hline Age Range (per year) & \multicolumn{2}{|c|}{ Surveyed Population } & \multicolumn{2}{c|}{ Prevalence } \\
\hline Sex & Effective & Percent (\%) & (Cas +) (\%) & (Cas-) (\%) \\
\hline Less than 1 & 18 & 2.7 & $0(0)$ & $18(100)$ \\
\hline $1-5$ & 46 & 7.02 & $0(0)$ & $46(100)$ \\
\hline $6-14$ & 125 & 19,08 & $3(2,4)$ & $122(97.6)$ \\
\hline 15 and more & 466 & 71.1 & $16(3,4)$ & $150(96.6)$ \\
\hline Total & 655 & 100 & $19(2.9)$ & $636(97.0)$ \\
\hline
\end{tabular}

Source: Authors (2017).

Table 3: Distribution of people tested for HIV by age group.

\begin{tabular}{|c|c|c|}
\hline Marital Status & Frequency & Percentage \\
\hline HGR / Kenge & 13 & 68 \\
\hline CS. Fence & 4 & 21 \\
\hline CS. Dream & 2 & 11 \\
\hline Total & 19 & 100 \\
\hline
\end{tabular}

Source: Authors (2017).

Table 4: Seroprevalence by year of screening.

\begin{tabular}{|c|c|c|}
\hline Marital Status & Frequency & Percentage \\
\hline 2015 & 16 & 84 \\
\hline 2016 & 3 & 16 \\
\hline Total & 19 & 100 \\
\hline
\end{tabular}

Seroprevalence by year of screening.

Table 5: Seroprevalence according to the place of residence of the respondents.

\begin{tabular}{|c|c|c|}
\hline Residence & Frequency & Percentage \\
\hline District Congo & 6 & 31.57 \\
\hline Kikwit district & 5 & 26,31 \\
\hline District Bakali / SAS & 5 & 26,31 \\
\hline Neighborhood EPOM & 1 & 5.26 \\
\hline Masikita district & 2 & 10.52 \\
\hline Total & 19 & 100 \\
\hline
\end{tabular}

Source: Authors (2017). 


\section{Analysis of Socio- Educational Factors Related to} Seroprevalence

The social factors educational not a positive influence on seroprevalence. As an illustration, Table 6 indicated that the Pelende (31.5\%), Mbala (20.4\%), Suku (18\%), Yaka (13\%) and Hungani $(7.1 \%)$ are the largest language groups in the surveyed population, followed by Luba ( $2,8 \%$ ) , Swahili (2.6\%) and Ngala $(0.9 \%)$. The other language groups represent only $3.6 \%$ of the surveyed population (Table 6). On the 655 interviewed subjects, more than 235 were from religion Protestant e (36\%), followed by the Catholics (24.2\%), kimbanguists (18.2\%) , de nonbelievers (8.3\%), musulmans (6.6\%), and 34 Other topics are coming from various religious onfessions c (or 5, 2\%) (Table 7). Report with the perception of respondents are HIV infection, information collected e a u T able 8 shows that 303655 subjects perceive HIV as a disease ronique ch incurable $(46.2 \%) ; 252$ subjects ( $38.4 \%$ ) consider it a disease of lovers; close to 100 Topics on the 655 said that all of my exposed to the risk of HIV infecté (15.2\%), and; a very small proportion pens é to e nvoutement (0.2\%) (Table 8).

Table 6: Sociolinguistic characteristics of the respondents.

\begin{tabular}{|c|c|c|}
\hline Linguistic Group & Frequency & Percent (\%) \\
\hline Yaka & 85 & 13.0 \\
Pelende & 206 & 31.5 \\
Mbala & 134 & 20.4 \\
Suku & 118 & 18.0 \\
Hungani & 47 & 7.1 \\
Ngala & 6 & 0.9 \\
swahili & 17 & 2.6 \\
L ub a & 18 & 2.8 \\
Other groups & 24 & 3.6 \\
\hline Total & 655 & 100 \\
\hline
\end{tabular}

Source: Authors (2017).

Table 7: $\mathrm{C}$ ra ct i s ticks sociore the igieux investigations.

\begin{tabular}{|c|c|c|}
\hline Linguistic Group & Frequency & Percent (\%) \\
\hline Catholic & 159 & 24.2 \\
Kimbanguists & 119 & 18.2 \\
Muslim & 43 & 6.6 \\
Non-believers & 54 & 8.3 \\
protestant & 236 & 36 \\
Other & 34 & 5.2 \\
denominations & & \\
\hline Total & 655 & 100 \\
\hline
\end{tabular}

Source: Authors (2017).

Table 8: Perception of respondents of HIV infection.

\begin{tabular}{|c|c|c|}
\hline $\begin{array}{c}\text { Nature of HIV / } \\
\text { AIDS }\end{array}$ & Frequency & Percentage \\
\hline M incurable chronic & 303 & 46.2 \\
ise ase & 252 & 38.4 \\
M ise ase lovers & 99 & 15.2 \\
Everyone's sickness & 1 & 0.2 \\
envoutement & & \\
\hline Total & 655 & 100 \\
\hline
\end{tabular}

Source: Authors (2017).

Concerning modes of transmission, the Table 9 reveals that jets 465 susur 655 asserted $u$ have some knowledge of HIV transmission (71\%) against 190 quido contains have not ent at all (29\%). En effet, on the s 465 people who knew the mode of transmission, 186 cited the sexual mode ( $39.9 \%$ ) ; 25.4\% the blood mode (either 118 subjects ); Parental m ode was cited by 93 people (19.9\% ); 69465 people cited both the sexual way and the s anguin mode (ie $14.9 \%$ ) (Table 9). As for the prevention methods, Table 10 indicates that 465 people sister recognized the corrective $t$ use condoms s c As effective means of AIDS prevention (26.1\%); 85 pe r PERSONS (18.3\%) have spoken ed the integration of prevention of HIV transmission from mother to child activities (PMTCT); 28 subjects targeted the s ecurity transfusion (6\%), and; 29 subjects indicated the personal use of objects ranchants $t$ (or 6.3\%). Very little o u nt re conn early detection of HIV as a strategy for prevention against the infection HIV (14 people of 465, or 3\%). Cepuring 142465 be $32 \%$ cited both condoms use and PMTCT; 14 people, silo $3 \%$ cited the first three modes. S Only $4.5 \%$ of respondents (n it 21 people out of 4 65) cited're all $\mathrm{c} \mathrm{m}$ odes (Table 10).

Table 9: Knowledge of respondents on the mode of transmission of HIV / AIDS.

\begin{tabular}{|c|c|c|}
\hline Mode transmission & Frequency & Percentage \\
\hline Parental & 69 & 14.9 \\
Sexual & 186 & 39.9 \\
sanguine & 118 & 25.4 \\
Sexual \& Sanguine & 93 & 19.9 \\
\hline Total & 19 & 100 \\
\hline
\end{tabular}

Source: Authors (2017).

Table 10: Knowledge of the respondents on how prevention of HIV / AIDS.

\begin{tabular}{|c|c|c|}
\hline Mode transmission & Frequency & Percentage \\
\hline PMTCT & 85 & 18.3 \\
A wise condom & 121 & 26.1 \\
PMTCT \& U wise condoms & 142 & 32.0 \\
These first three modes & 14 & 3.0 \\
S ecurity transfusion & 28 & 6,0 \\
U wise personal sharps & 29 & 6,3 \\
D épistage early HIV & 14 & 3,0 \\
All these modes & 21 & 4,5 \\
\hline Total & 655 & 100 \\
\hline
\end{tabular}

Source: Authors (2017).

Finally, inferential statistics is detected s relationships strongly negative and significant between c,es socio-educational factors retain and seroprevalence; but $\mathrm{l}$ e s factors socioethnic $\mathrm{n}$ 'had no influence on the prevalence (Table 11). The board 11 shows that the perception of HIV infection $\left(\mathrm{Kh}^{2}=17.79, \mathrm{df}=4 ; \mathrm{p}=0.00\right)$ and the fact to know the modes of transmission of AIDS $\left(\mathrm{K} \mathrm{h}^{2}=19.43\right.$, $\mathrm{df}=4 ; \mathrm{p}=0.00)$ and its prevention $\left(\mathrm{Kh}^{2}=58.60, \mathrm{df}=8 ; \mathrm{p}=0.00\right)$ avai $t$ a pleasant effect on the seroprevalence. But that there is no relationship between Vait has seroprevalence and all social and ethnic factors cited investigated by the $s$ and $r$ that could positively 
affects, including membership religi honest $\left(\mathrm{Kh}^{2}=0.37\right.$; $\mathrm{df}=6, \mathrm{p}$ $=0,885)$ and lingu i sti that $\left(\mathrm{Kh}^{2}=11.51, \mathrm{ddl}=9 ; \mathrm{p}=0,12\right.$ 3 ). So, possession of accurate information on a transmission and prevention of HIV / AIDS it will be the pillar of any strategy that fight against this scourge of the 2 s century.

Table 11: Factors associated socio educational e d seroprevalence at Kenge.

\begin{tabular}{|c|c|c|c|c|}
\hline Variable & $\mathbf{K h i}^{\mathbf{2}}$ & $\mathbf{d ~ d l}$ & $\mathbf{p} \leq$ & Decision \\
\hline Language & 11,51 & 9 & 0,123 & Ho Accepted (85\%) \\
\hline Religion & 0.37 & 6 & 0.885 & Ho Accept ed (15\%) \\
\hline $\begin{array}{c}\text { Perception of HIV } \\
\text { infection }\end{array}$ & 17,79 & 4 & 0,003 & Ho Rejected (99\%) \\
\hline $\begin{array}{c}\text { Knowledge of } \\
\text { u transmission } \\
\text { mode }\end{array}$ & 19.43 & 4 & 0,001 & Ho Rejected (99\%) \\
\hline $\begin{array}{c}\text { Knowledge of u } \\
\text { prevention mode }\end{array}$ & 58,60 & 8 & 0,000 & Ho Rejected (99\%) \\
\hline
\end{tabular}

Source: Authors (2017).

\section{Discussion of Results}

\section{Discussion on the S Socio - Demographic Characteristics of the Respondents}

This study conducted in the city of Kenge during the period of th from January 2015 to June 2016 revealed a general HIV prevalence in the order of $2.9 \%$. When s even from a sample greatly reduced, c es s results indicate that seroprevalence of the city of Kenge is much higher, compared with the national average of $1.1 \%$ set by the Sero-Surveillance Report of UNAIDS (2011) and WHO (2011). Indeed, the sister more than 150,000 inhabitants that includes the town of Kenge, only 655 people $(0.43 \%)$ are on the e s se detected in the selected FOV. This very low enrollment rate in HIV / AIDS testing proves to the satisfaction of the population's low willingness to know its HIV-positive status. These results corroborate those of Barrere (2016) who, in his study of " knowledge, attitudes and behavior vis-à-vis STI / AIDS " found that in Cameroon only $5 \%$ of women and $7 \%$ men have performed an HIV test and received the results the last 12 months. This low screening rate can also be explained by the low number of HIV diagnoses [20,21].

This study also showed that HIV prevalence was $1.7 \%$ for men and $3.8 \%$ for women. Several studies have confirmed the e fact that women are increasingly expos ed and now constitute nearly half of the 37.2 million adults (15 to 49) living with HIV in the world. The SSA is the hardest hit region in the world, with nearly $60 \%$ of female adults living with HIV, or 13.3 million cases [12,22]. The results of the EDS-2008 relayed by PNMLS (2008) also confirmed the fact that women are significantly affected by the AIDS epidemic than men. This high rate of infection among young women and adolescent girls can be explained by the "sugar daddies" phenomenon, where older men barter gifts and money for unprotected sex, as is the case in Africa. South (WHO, 2016). This situation is also observed in the town of Kenge. Indeed, the distribution of HIV positive has shown that e only old patient s over 14 years, those females and living in Congo neighborhoods, Kikwit and Bakali / SAS, located on the National No. 1 were the most affected. No cases were detected in slices of lower age century at age 5 , while s age bracket from 6 to 14 years and more than 14 years o nt recorded respectively es prevalence $s$ of the order of 2.4 and $3.4 \%$. This is precisely justified risk factor for the best- known HIV transmission, including intensive sexual activity.

The latter increases from the age of 15 when young people do not have enough knowledge about HIV prevention [21]. The survey on mortality, the morbidity and the use of services (EMMUS-V) directed e by the Ministry of Public Health and Population (MSPP) in Haiti in 2012 has dice showed that 2.2 \% of people tested for 15-49 years are infected with HIV [22]. This $r$ UTCOME deemed significant lies less in what the u i found in the city of Ke n g e in 2016. Infection in children aged 6-14 may be partly attributed to transfusions and injections made without respect for protection standards. Moreover, the absence infection nd year tranche of age inf e higher in a year some $t$ be consécuti ve integration of the transmission of HIV from mother to child prevention activities ( PMTCT), in line with UNAIDS guidance, which advocates a triple zero goal: Zero new infections due to HIV; Zero discrimination nt, and ; Zero cases of death due to HIV. As for the origin of the detected event, the present e study demonstrated that the highest proportion is observed Neighborhood Congo (with 31,6\%), followed consecutively of Kikwit neighborhoods and Bakali / SAS (26.3\% each). T ll these neighborhoods are located on the National No. 1 where the o n observes migratory flows and intense commercial activity s. There re are several places of ease, of enjoyment e $t$ food supply. These include bars, hotels, restaurants, shops and e s markets, without forgetting the central parking Kenge, commonly called "B back".

That which exposes the population to risk behavior likely s to foster the spread of HIV / AIDS. Its n ' est therefore not surprising to see the s district s Device Masikita et EPOM 10.5 and 5.3\% of the cases detected shine with a very low prevalence, estimated at respectively. Analysis t e mp orelle the pr e valence of HIV / AIDS shows that 16 out of 19 positive cases were te te TROUBLE- ed in 2015 (84.2\%) against 3 cases in 1 st half of 2016 (ie 15.7\%). Although the study focused on the first half of the year, the various studies currently show a downward trend in HIV infection worldwide. Between 2000 and 2016, the number of new infections fell by $39 \%$ and that of HIV-related deaths fell by a third, with 13.1 million lives saved thanks to $\mathrm{x}$ Antiretroviral Treatments (ART). That Equals Does reflects the considerable efforts made by the national fight against HIV programs, with the support of civil society and various development partners (WHO, 2017). The awareness is so important in the implementation of art programs of fight against HIV / AIDS.

\section{Discussion on Socio- Educational Factors Associated with HIV / AIDS}

$\mathrm{L}$ has awareness $\mathrm{r}$ e po s e mainly on socio -ethniques and educational conditioning the thinking e $t$ s e behavior of the general 
population. These factors include religion and the language or ethnic group, as well as instruction on HIV transmission and prevention training. In general, religion and ethnicity s have often if $g$ nificatifs in determining seroprevalence and in the s studies conducted entirely under other skies [23-25]. But these factors had no particular significance for the explanation of seroprevalence in the Kenge Health Zone. Hence the acceptance of the null hypothesis which establishes a clear difference between socio-ethnic factors and seroprevalence. In fact, predominantly Protestant (36\%), Catholic s (24.2\%), Kimbanguists (1 8.2\%), Muslims and nonbelievers (8.3\%), the respondents were either associated to PLHIV, as the $\mathrm{l}$ es that are leu rs tribes or native languages. knowledge of respondents on the transmission or prevention of HIV / AIDS and seroprevalence. Sawadogo (2007) concluded t alo r However, there was no particularly significant reason for not accepting the alternative hypothesis that there was not a significant difference between $s$ that e the inadequate knowledge of the channels of HIV transmission appears to be a factor aggravating seroprevalence following non u sing the services VCT ( VCT ).

This inadequate knowledge shines clearly in the way in which people PERC oiv e $n t$ HIV. Many of the respondents are of the opinion that the V IH is a chronic disease i ncurable (46.2\%), while others consider it a disease of love ( $38.4 \%$ ) or that everyone is supposed to be exposed to the risk of i nfect ion HIV ( $15.2 \%$ ) , or that it is a flow $(0.2 \%)$. And even though $71 \%$ claim to know the modes of transmission of HIV, 2 9\% do not know at all. Only 39.9\%, 25.4\% and $14.9 \%$ have respectively cited s exe as m ode main transmission of this infection, followed by m blood ode e $t$ of fashion s sexual and s anguin both. Yet Z Igani (2004) found in his study that only sexual intercourse is the most connue of all the es investigated s (99\%). Regarding the prevention, Zigani (2004) reveals that condom es tl is the tactic most famous ed es respondents (respectively $56 \%$ and $70 \%$ of e ow l' have re known). However, only $26.1 \%$ of the subjects in our sample have recognized the correct use of condoms sc A s effective means of prevention of HIV. D ' at $t r$ e s, in this case $18.3 \%$ have $p$ ense the treatment Prévention of Transmission of HIV M era in Enfant (PMCT) ; 32\% cited both condom use and PMTCT , and; $6 \%$ respectively p ense to the s transfusion ecurity and personal use objects $t$ ranchants. Only a very few have re conn u early detection of HIV how prevention strategy against infection with HIV (3\%).

\section{Conclusion}

This study you are carrying on the sociocultural factors associated with the prevalence of HIV / AIDS in the city of Kenge has established a rate of $2.9 \%$ rate considered higher than PNMLS which sets national prevalence at $1.1 \%$. The age of more than 14 years, female gender and neighborhoods urbanized, or cosmopolitans were the most affected s. Thus, Congo, Kikwit and Bakali / SAS districts, located along the $\mathrm{N}^{\circ} 1$ national road, have been the are knowledge of the population about modes of transmission and prevention of HIV infection. The most affected since they sheltered e nt several places of 'aisanc e and re enjoyment, making the following e to significant emigration and to sexual activity in $\mathrm{t}$ ensive. This seroprevalence seems to be aggravated by the nonuse of voluntary counseling and testing (VCT) services, due to the insufficiency of the socio- ethnic and educational factors that condition the thinking and behavior of the population in general. such as religion, language group and ethnicity, cannot face $r$ among the determinants of prevalence of HIV / AIDS infection in the town of Kenge [26-38].

\section{Recommendations}

As a recommendation, the authors of this article strongly challenge the government congolais to be able to support activities against HIV / AIDS in the Province Kwango in general and the city of Kenge in particular. Awareness-raising activities on condom screening and condom use, condom and ARV distribution, and case management are all precautionary measures that need to be taken to reduce the prevalence of HIV / AIDS and curb the spread of HIV / AIDS. plague of this pandemic in Kenge.

\section{References}

1. Annan K (2004) Living in the world facing HIV/AIDS, Information for nations and their families. Geneva: UN AIDS, Switzerland.

2. Arvieux C (2005) Epidemiology of HIV Infection in 2005, The Medical Press 34(10Supply1): 16-22.

3. Barrère M (2016) Knowledge, attitudes and behaviors towards STIs / AIDS.

4. (2014) CENI, Independent National Electoral Commission 2014. Report of the enlistment of the electors. Kinshasa: Independent National Electoral Commission (CENI), Democratic Republic of Congo.

5. Coghlan B (2009) Update on mortality in the Democratic Republic of Congo: Results from a third nationwide survey. Disaster Medicine and Public Health Preparedness 3(2): 88-96.

6. From Sardan, O Diarra, Moumouni (2006) The management of PVVIH and ARV compliance in Niamey (socio-anthropological approach). Niamey: L ASDEL, Republic of Niger.

7. (2009) Guillaumic Foundation 2009. HIV / AIDS The collapse of a myth. What African epidemic?

8. Furaha B (2007) The socio-economic impact of micro-loans granted to PLHIV.

9. Hama M (2010) Impact of ARVs on the evolution of biological parameters in patients followed at CSREF the Town 4 of Bamako. Bamako: Faculty of pharmacy and odonto-stomatology medicine, University of Bamako, Republic of Mali.

10. Hargreaves (2008) HIV infection in sub-Saharan Africa. AIDS (Jan 2002) 30, 22(3): 403-414.

11. (2006) Harvard University. The HIV / AIDS and Gender-Based Violence (GBV) Literature Review. Boston, MA: School of Public Health Press, Harvard University, USA.

12. Makano A (2007) Support for people living with HIV / AIDS in Butembo City, Ruwenzori Official University, Faculty of Social, Political and Administrative Sciences, Democratic Republic of Congo.

13. Mellini L, Godenzi A, De Puy J (2004) AIDS is not said: Analysis of forms of secrecy around HIV / AIDS. Paris: The Harmattan, French Republic.

14. (2007) MINIPLAN, Ministry of Planning and MINISANTE, Ministry of Health 2007. Demographic and Health Survey (EDS-RDC I 2005 -2006). 
Kinshasa: Ministry of Planning (MINIPLAN) and Ministry of Health (MINI S AN TE), Democratic Republic of Congo.

15. (2010) MINISANTE, Ministry of Health 2010. National Plan of Sanitary Development. Kinshasa: MINISANTE, Democratic Republic of Congo.

16. (2016) MINISANTE, Ministry of Health. SNIS Reports 2016. Kenge: Kwango Provincial Health Division (DPS / Kwango), Democratic Republic of Congo.

17. Moha M (2011) Even the food, you get tired of eating it. PLHIV and drugs in Niger. Studies and Works $n^{\circ} 94$ (November 2011).

18. MSF, Médecins Sans Frontières (2008) Accompanying the child patient infected with HIV. Paris: Médecins Sans Frontières (MSF), French Republic.

19. (2012) MSPP, Ministry of Public Health and Population 2012. Mortality, Morbidity and Utilization Survey (EMMUS-V). Havana: Haiti HIV / AIDS, Haiti.

20. (2012) European Monitoring D rogues and Drug Addiction 2012. Report of the European Monitoring Center for Drugs and Drug Addiction 2012.

21. (2002) WHO, World rganisation of S ant é Report on HIV / AIDS. Geneva: WHO Secretariat, Switzerland.

22. (2016a) WHO, World rganisation of S ant é Global Strategy for the Health Sector Against HIV 2016-2021 towards the elimination of AIDS. Geneva: WHO Secretariat, Switzerland.

23. (2016b) WHO, World rganisation of S ant é Update on the HIV / S IDA epidemic in 2016. Geneva: WHO Secretariat, Switzerland.

24. (2017) WHO, World rganisation of S ant é HIV / AIDS, Aide Memoire (updated November 2017). Geneva: WHO Secretariat, Switzerland.

25. (2004) UNAIDS / WHO, Program of N United ations for against L Utte against the S IDA, and O World rganisation of S ant é (2004) The number of women living with HIV is increasing in every region of the world, UNAIDS / WHO Joint Press Release of 23 November 2004. Geneva: WHO Secretariat, Switzerland.

26. (2004) UNAIDS, Program of N United ations for against L Utte against the S IDA. World Report on the HIV Epidemic. Geneva: Library of the WHO, Switzerland.

27. (2007) UNAIDS, Program of N United ations for against L Utte against the SIDA. Sero-surveillance report. Geneva: Library of the WHO, Switzerland.

28. (2011) UNAIDS, Program of N United ations for against L Utte against the SIDA. World Report on the HIV Epidemic. Geneva: Library of the WHO, Switzerland.

\section{ISSN: 2574-1241}

\section{DOI: 10.26717/BJSTR.2019.18.003137}

Perpétue Zenga Mukinda. Biomed J Sci \& Tech Res

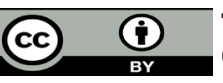

This work is licensed under Creative Commons Attribution 4.0 License

Submission Link: https://biomedres.us/submit-manuscript.php
29. (2012) UNAIDS, Program of N United ations for against L Utte against the SIDA (2012) World Report on HIV. Geneva: Library of the WHO, Switzerland.

30. (2006) NACP, Program National L Utte against the SIDA (NACP) Manual of monitoring and evaluation. Kinshasa: Secretariat Program National L Utte against the SIDA (NACP), DR Congo.

31. (2010) NAP Program National L Utte against the SIDA. Clinical guide for the care of PLHIV in the DRC. Kinshasa: Secretariat Program National L Utte against the SIDA (NACP), Democratic Republic of Congo.

32. (2013) NAP, Program National L Utte against the SIDA. Tutors' checklist on HIV / AIDS care. Kinshasa: Secretariat u Program National L Utte against the SIDA (NACP), Democratic Republic of Congo.

33. (2008) PNMLS, Program National Multisectoral of L Utte against the $S$ IDA 2008. Epidemiological data of HIV/AIDS in DR Congo. Kinshasa: Secretariat u Program National Multinational of L Utte against the S IDA (PN M LS), Democratic Republic of Congo.

34. (2012) PNMLS, Program National Multisectoral of L Utte against the S IDA 2012. A contribution of activity on the HIV/AIDS RD. Congo 2012. Kinshasa: Secretariat Program National Multinational of L Utte against the S IDA (PN M LS), Democratic Republic of Congo.

35. (2013) PNMLS, Program National Multisectoral of L Utte against the S IDA 2013. Progress report on the response to HIV / AIDS in DR Congo 201 3. Kinshasa: Secretariat of PN M LS, Democratic Republic of Congo.

36. Roux, P Rey, JL, Sehonou J, Certain, A (2004) The one-month compliance of AIDS patients included in the Benin antiretroviral drug access initiative. Bull Soc Pharm. Bordeaux 143: 19-30.

37. (2012) Rwanda MOH, Ministry of Health 2012. Guide for taking HIV-infected people. Kigali: Ministry of Health $(\mathrm{MoH})$, Republic of Rwanda.

38. Kenge (2016) City of Kenge 2016. Statistics of the Kwango Population 201 6. Kenge: Office of the Town Hall of the City, Democratic Republic of Congo.

39. WHO (2004) Violence against women and HIV / AIDS: Critical intersections. World Health Organization.

40. Zigani (2004) Studies of the factors limiting the low use of voluntary counseling services by people practicing in the informal sector in the city of Ouaga dougou - C as small traders. Diploma of Higher Technician Diploma in Nursing and Midwifery. Ouaga dougou: National School of Public Health (CFDS), Burkina Faso.

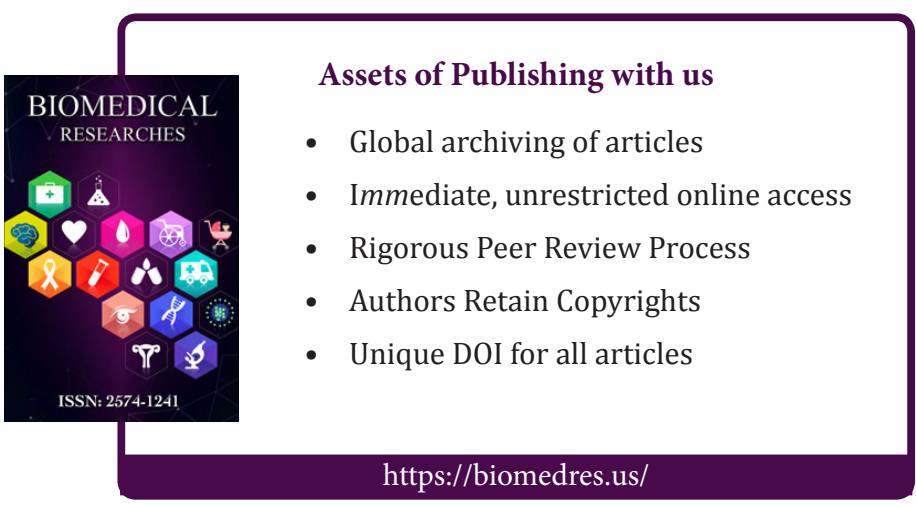

Copyright@ Perpétue Zenga Mukinda | Biomed J Sci \& Tech Res| BJSTR. MS.ID.003137. 